\title{
High-throughput capturing and characterization of mutations in essential genes of Caenorhabditis elegans
}

\author{
Jeffrey Shih-Chieh Chu ${ }^{1 *}$, Shu-Yi Chua ${ }^{2}$, Kathy Wong ${ }^{1}$, Ann Marie Davison ${ }^{3}$, Robert Johnsen², David L Baillie ${ }^{2}$ \\ and Ann M Rose ${ }^{1}$
}

\begin{abstract}
Background: Essential genes are critical for the development of all organisms and are associated with many human diseases. These genes have been a difficult category to study prior to the availability of balanced lethal strains. Despite the power of targeted mutagenesis, there are limitations in identifying mutations in essential genes. In this paper, we describe the identification of coding regions for essential genes mutated using forward genetic screens in Caenorhabditis elegans. The lethal mutations described here were isolated and maintained by a wild-type allele on a rescuing duplication.
\end{abstract}

Results: We applied whole genome sequencing to identify the causative molecular lesion resulting in lethality in existing C. elegans mutant strains. These strains are balanced and can be easily maintained for subsequent characterization. Our method can be effectively used to analyze mutations in a large number of essential genes. We describe here the identification of 64 essential genes in a region of chromosome I covered by the duplication sDp2. Of these, 42 are nonsense mutations, six are splice signal mutations, one deletion, and 15 are non-synonymous mutations. Many of the essential genes in this region function in cell cycle, transcriptional regulation, and RNA processing.

Conclusions: The essential genes identified here are represented by mutant strains, many of which have more than one mutant allele. The genetic resource can be utilized to further our understanding of essential gene function and will be applicable to the study of $C$. elegans development, conserved cellular function, and ultimately lead to improved human health.

Keywords: Whole genome sequencing, EMS, Mutagenesis, Essential genes, Balanced mutation, Lethal mutation, C. elegans, Cell cycle

\section{Background}

The proper development and viability of an organism is dependent on a group of genes called essential genes. In humans, gene essentiality has been long associated with many diseases such as miscarriages $[1,2]$, heritable diseases, and cancer [3]. Recent studies have shown that over-expression of some essential genes promotes cell proliferation in cancer [4]. Due to its importance for survival, essential genes have been targets for new therapeutics or antimicrobials [5]. To effectively study essential

\footnotetext{
* Correspondence: jeff.sc.chu@gmail.com

'Department of Medical Genetics, University of British Columbia, Vancouver, Canada

Full list of author information is available at the end of the article
}

genes, generating lethal alleles in model systems is required. In the nematode Caenorhabditis elegans, the essential gene set is the largest set of genes and is estimated to contain $25 \%$ of all the genes [6-9]. Using RNAi, about 3500 genes have been annotated as essential (data collected from WormBase $[10,11]$ ). Inparanoid, a sequence based orthology inference tool, detects about $40 \%$ of the C. elegans genes are orthologous to the human genes. But approximately $60 \%$ of the essential genes show clear human orthologs, showing high conservation of essential genes, which makes $C$. elegans an excellent platform for examination of essential gene functions that are relevant to human health. Many important genes, such as let-60/Ras [12] and let-740/dcr-1 [13,14], were 
first discovered through $C$. elegans genetics. However, the genetic resource for studying these genes is severely lacking. Even with the concerted community effort such as the C. elegans Deletion Mutant Consortium [15], mutations in many essential genes are still lacking in the knock-out collection. The consortium have generated close to 6000 knock-out strains since 1998, but only 1436 essential genes are in the current collection [16,17]. In addition to the considerable time and effort required to generate a single knock-out allele, an outstanding disadvantage of the targeted deletion approach is that extra effort is needed to balance the lethal mutation [18]. Recently, the Consortium has adopted a procedure of random mutagenesis followed by whole genome sequencing (WGS) to generate and identify a large number of mutations [15]. Although this project can generate more mutations in shorter time, their method does not capture mutations that exhibit lethal phenotypes, and thus, essential genes are selected against. This outcome indicates thousands of essential genes do not have knockout alleles.

To complement the effort of the $C$. elegans community, we took advantage of the balancer system, which was developed 30 years ago for capturing and maintaining lethal mutations, with the next-generation DNA sequencing technologies. Almost $70 \%$ of the C. elegans genome have been successfully balanced by large genomic rearrangements [18]. By mutagenizing a pre-balanced strain removes the need to perform additional genetic crosses to balance a lethal mutation. The balancer system, designed specifically to capture and maintain lethal mutations, is the system of choice for generating mutations in essential genes. Such screens have been carried out for regions in chromosome I $[19,20]$, II [21], III [22], IV [23-26], V [27], and X [28,29]. In our laboratories, we have generated over 1350 lethal mutations that fall into 486 complementation groups.

The next hurdle in the analysis of essential genes is the molecular identification of the genomic lesion, which to date has involved an enormous effort. Traditional methods of gene cloning that rely upon candidate identification of mapped mutations can take months or years. This geneby-gene approach was only able to characterize 30 essential genes from our library to date. This problem has been difficult to solve until the recent advances in sequencing technology. To address the problem of coding region identification, we have recently developed a fast and scalable pipeline that takes advantage of whole genome sequencing and bioinformatics analysis to identify the causal mutation responsible for the lethal phenotype [30]. Recent studies, including our initial analysis of let-504 [30], have shown that whole genome sequencing is an efficient and cost-effective approach to identifying the encoded gene product especially when there are additional alleles that can be sequenced to provide confirmation [30-34]. In this paper, we describe our approach of combining an established mutagenesis technique with the latest sequencing technology in order to close the gap in the essential gene knock-out collection.

\section{Results and discussion}

Chromosome I left has a high percentage of essential genes The leftmost 7.3 Mbp of chromosome I has the highest percentage of mapped essential genes and closest to saturation with 237 essential genes isolated and mapped [19]. The mutant strains were derived by mutagenizing KR235 [dpy-5 (e61), +, unc-13 (e450)/dpy-5(e61), unc-15(e73), +; $s D p 2$ ] with a low dose of EMS and isolating let-x $d p y-5$ unc-13 homozygotes rescued with a third wild-type allele of $d p y-5$ and let- $x$ balanced by free duplication $s D p 2$ [35] (see schematic in Additional file 1). In order to position the genes, mutations were mapped into 60 zones using a combination of three-factor mapping and complementation to a series of duplications and deficiencies [19]. Within zones, lethal mutants were inter-complementation tested. The earliest developmental arrest stages were determined for each complementation group [19]. The candidate lesions are present in two copies and rescued by a third wild-type allele on $s D p 2$. Thus, our high throughput identification method focused on finding heterozygous mutations that exhibit an allelic ratio between the range of $40 \%$ to $90 \%$ [30]. In order to assess the accuracy of our recently developed high throughput method [30], we selected 81 genes from this set with the criteria that they formed a complementation group having more than one allele (Additional file 2). The extra alleles provide an added resource for validation. We sequenced 10 indexed genomic DNA samples per Illumina HiSeq lane and obtained a total of $385 \mathrm{Gbp}$ of sequence. The sequencing reads were aligned using BWA [36] to the WS200 C. elegans reference sequence. We achieved 30X coverage on average across the whole genome and an average of 35X coverage in coding elements. In the case of two strains, only $6 \mathrm{X}$ coverage was obtained: let-369(h125) and let-594(h407). Genomes from these two strains were removed from subsequent analysis.

\section{The mutational landscape provided a quality check}

Our first analytical step, as a quality check, was to confirm the presence of the $d p y-5$ (e61) and unc-13 (e450) mutations in each genome. For unc-13, the expected variant ratio should be $100 \%$ because the duplication does not extend far enough to provide an additional wild-type allele. For $d p y-5$ however, there is a wild-type allele on $s D p 2$, and thus we would expect to see a $66 \%$ variant ratio. We found the expected ratios in 76 of the 79 genomes. Three genomes deviated from the norm: let-516(h144) is missing both $e 450$ and $e 61$ (all the reads supported the reference sequence); let-388(h88) is missing e61; let-393(h225) has e61, but with a $33 \%$ ratio 
rather than the expected 66\%. We examined these strains for the presence of the duplication $s D p 2$. When the duplication is present, the read depth is $33 \%$ greater in the first $7 \mathrm{Mbp}$ of chromosome I than for rest of the chromosome. Our analysis showed that none of these three genomes showed any depth difference (Additional file 3$)$. It is likely these strains do not carry $s D p 2$. Although $s D p 2$ does not crossover with the normal homologs at a readily detectable frequency, rare exchange events can occur resulting in subsequent loss of the duplicated fragment [37]. These three strains were not analyzed further.

\section{Coding sequence correlated with high confidence}

We analyzed the parental strain KR235 and identified 571 SNVs and 167 small indels that show $>40 \%$ read support on Chromosome I when compared to the C. elegans WS200 reference using VarScan (see Methods). These mutations represent the background mutations in which the lethal mutations were maintained. For the remaining 76 genomes, we filtered out the background mutations and found on average 44 SNVs that show $>40 \%$ allelic ratio in the $s D p 2$ region. Most of the SNVs are $\mathrm{G}>\mathrm{A}$ or $\mathrm{C}>\mathrm{T}$ changes as expected and previously observed after EMS treatment [30,38]. We also found an average of 7 small indels of 1-2 bps. We categorized each mutation as either nonsense, missense, synonymous, splice signal disruption, frame shifting indel, frame preserving indel, or noncoding mutation. Noncoding mutations were defined as any mutation located outside of coding regions. A full list of SNVs and indels, for each strain, is available on our server at http://lethal.mbb.sfu. ca/jschu/essential_genes.

We identified candidate mutations for the 76 genomes using our bioinformatics pipeline that we developed previously [30] (see also Methods) and validated a subset of our candidates by sequencing a second allele or by complementation testing (Table 1). Nine of our candidate lesions were in genes that had been previously identified and published. In a few cases, candidates expected to be in separate genes were located in the same coding region. These observations were confirmed by further genetic complementation tests (Additional file 4). Previously identified let-631 and let-103 were found to be allelic to let-363. As a result, let-363 gains three new $s D p 2-$ balanced alleles $(h 216, h 451, h 502)$ in addition to the nine existing ones. let-519 and let-104 are allelic to let526 and thus let-526 gains four new alleles: $h 799, h 373$, $h 405$ and $h 526$. let-630 fails to complement let-596 and now has five alleles: $h 355, h 702, h 432, h 782$, and $h 258$. Thirty-five candidates were tested by sequencing a second allele using previously published complementation data [19]. Of these, we confirmed 29 identities. All in all, we tested 48 candidates and confirmed 42 (87.5\%).
For the remaining 28 genomes, we have high confidence in the identity of 22 genes based on their map position. Thus, including previously described let-504, we now have coding region assignments for 64 let-genes in the $s D p 2$ region. Because the genes in this study all have multiple alleles, thus by inference, we have confidently identified the coding regions affected in a total of 259 mutant strains (Additional file 2).

Seven of these genes have been molecularly identified and phenotypically described. let-603, an aurora kinase [46], and let-605, the cyclin E, had severe gonadal defects [56]. let-355, a DEAD box helicase, and let-384, an integrator subunit, failed to develop gametes [56]. let-370, let599, and let-604 produced malformed embryos that were not laid or hatched [56]. let-370 encodes a hexaprenyl pyrophosphate synthetase that is associated with Parkinson's disease [51]. let-599 encodes the $\mathrm{N}$-acetyl transferase nath-10. let-604 encodes $m d t-18$, a mediator subunit. A comprehensive summary of the let- encoded products is given in Table 1.

\section{Novel knock-out alleles provide new genetic resources}

We have generated new alleles for 13 genes that currently have no knock-out alleles available: let-595 (imb-1), let362 (Y71G12B.8), rnp-6 (let-147), aars-2 (let-366), let-598 (F27C1.6), let-355 (T05E8.3), let-384 (C06A5.1), fars-1 (let-396), let-611 (C48E7.2), mdt-18 (let-604), acdh-5 (let383), rpb-5 (let-397), and let-630 (Y110A7A.19). Eight of these genes are predicted to have roles in essential basic functions such as transcription or translation. This is not surprising, because we expect genes that function in basic cellular processes to be essential and are best captured using balancer systems. Besides these novel alleles, we have provided additional loss of function alleles for many characterized genes (Table 1). Additional alleles affecting different parts of the gene may disrupt different domains providing an allelic series correlating with different phenotypes.

Genetic strains carrying heritable mutational changes provide a lasting resource that can be used in a variety of experimental conditions and compared to information gained from RNAi knock-down experiments. We crosschecked our high confidence list with the RNAi data annotated in WormBase to see if the lethal phenotype was observed in at least two RNAi experiments. Although for the most part, RNAi data agrees with our mutational data, not every gene was supported by RNAi. We found nine genes showing no lethal phenotype with RNAi and three genes showing lethal phenotype of variable penetrance (Table 1). Of the nine genes that show no RNAi lethal phenotype, six (inx-12, coq-1, lim-7, tag146, let-381, and let-503) have additional knock-out alleles that are lethal, suggesting RNAi did not reveal the null phenotype of these genes. The additional information 
Table 1 Coding DNA Sequence (CDS) identifications of let- genes

\begin{tabular}{|c|c|c|c|c|c|c|c|c|}
\hline Gene & Allele & Allele mutation & Molecular identity & Support & Confirmation status & Human ortholog & Associated human conditions & References \\
\hline lin-6/mcm-4 & h92 & $C>{ }^{*}$ & Mini chromosome maintenance & RNAi & Confirmed ${ }^{1}$ & MCM4 & $\begin{array}{l}\text { Natural killer cell and glucocorticoid } \\
\text { deficiency with DNA repair defect }\end{array}$ & [39] \\
\hline let-354/dhc-1 & h79 & $Q>*$ & Dynein heavy chain & Both & Confirmed ${ }^{1}$ & DYNC1H1 & $\begin{array}{l}\text { Charcot-Marie-Tooth disease, Mental } \\
\text { retardation, Spinal muscular atrophy }\end{array}$ & {$[40-42]$} \\
\hline let-502/rock & h392 & $Q>*$ & Rho associated kinase & RNAi & Confirmed ${ }^{1}$ & ROCK1 & & [43] \\
\hline \multirow[t]{3}{*}{ let-363/tor } & h98 & Splice variant & Tor kinase & Both & Confirmed ${ }^{1}$ & MTOR & pancreatic neuroendocrine tumors & {$[44,45]$} \\
\hline & $\mathrm{h} 420^{\mathrm{a}}$ & $Q>*$ & & & Confirmed $^{3}$ & & & \\
\hline & $\mathrm{h} 502^{\mathrm{a}}$ & Splice variant & & & Confirmed $^{3}$ & & & \\
\hline let-603/air-2 & h289 & $W>*$ & $\begin{array}{l}\text { Aurora-related serine/threonine } \\
\text { kinase }\end{array}$ & Both & Confirmed ${ }^{1}$ & AURKA & Susceptibility to colon cancer & {$[46]$} \\
\hline let-512/vps-34 & h797 & $P>S$ & phosphoinositide 3-kinase & & Confirmed $^{1}$ & PIK3C3 & & {$[47]$} \\
\hline let-381/foxf & h107 & splice variant & Forkhead transcription factor $F$ & K.O. & Confirmed ${ }^{1}$ & FOXF2 & & [48] \\
\hline let-607/bZip & h402 & $Q>*$ & Leucine zipper transcription factor & Both & Confirmed ${ }^{1}$ & CREB3L3 & & [49] \\
\hline let-504/E01A2.4 & h448 & $M>1$ & NFkB activating protein & Both & Confirmed ${ }^{1}$ & NKAP & & \\
\hline let-152/ccb-1 & h685 & $W>^{*}$ & Calcium channel subunit & & Confirmed $^{2}$ & CACNB2 & Brugada syndrome 4 & \\
\hline $\begin{array}{l}\text { let-355/hel/ } \\
\text { T05E8.3 }\end{array}$ & h81 & $Y>{ }^{*}$ & DEAD/H helicase & RNAi & Confirmed $^{2}$ & DHX33 & & \\
\hline $\begin{array}{l}\text { let-362/rhel/ } \\
\text { Y71G12B.8 }\end{array}$ & h86 & $\mathrm{R}>*$ & DEAD/H RNA helicase & RNAi & Confirmed $^{2}$ & $\mathrm{DDX} 27$ & & \\
\hline let-366/aars-2 & h112 & $Q>*$ & Alanine tRNA synthetase & RNAi & Confirmed $^{2}$ & AARS & Charcot-Marie-Tooth disease & {$[50]$} \\
\hline let-368/inx-12 & h121 & $W>^{*}$ & Innexin gap junction & K.O. & Confirmed $^{2}$ & & & \\
\hline let-370/coq-1 & h128 & $G>E$ & $\begin{array}{l}\text { hexaprenyl pyrophosphate } \\
\text { synthetase }\end{array}$ & K.O. & Confirmed $^{2}$ & PDSS1 & $\begin{array}{l}\text { Coenzyme Q10 deficiency, Parkinson's } \\
\text { disease }\end{array}$ & {$[51]$} \\
\hline let-389/nars-1 & h680 & $G>E$ & Asparagine tRNA synthetase & Both & Confirmed $^{2}$ & NARS & & \\
\hline let-396/fars-1 & h217 & $Q>*$ & Phenylalanine tRNA synthetase & RNAi & Confirmed $^{2}$ & FARSA & & \\
\hline let-522/hlh-2 & h735 & $W>^{*}$ & Helix loop helix transcription factor & Both & Confirmed $^{2}$ & TCF3 & Acute lymphoblastic leukemia & \\
\hline let-529/asd-2 & h238 & $Q>*$ & $\begin{array}{l}\mathrm{KH} \text { domain containing RNA } \\
\text { binding protein }\end{array}$ & RNAi & Confirmed $^{2}$ & QKI & Mental retardation & \\
\hline let-575/ptr-2 & h345 & $W>^{*}$ & Sterol sensing domain protein & RNAi & Confirmed $^{2}$ & PTCHD1 & Autism spectrum disorders & {$[52-54]$} \\
\hline let-585/inx-13 & h784 & $W>*$ & Innexin gap junction & RNAi & Confirmed $^{2}$ & & & \\
\hline let-595/imb-1 & h353 & $R>*$ & Importin & RNAi & Confirmed $^{2}$ & KPNB1 & & \\
\hline let-598/F27C1.6 & h213 & $Q>*$ & $\begin{array}{l}\text { U3 small nucleolar } \\
\text { ribonucleoprotein }\end{array}$ & RNAi & Confirmed $^{2}$ & UTP14C & & \\
\hline let-599/nath-10 & h290 & $L>F$ & $\mathrm{~N}$-acetyl transferase & Both & Confirmed $^{2}$ & NAT10 & & \\
\hline
\end{tabular}


Table 1 Coding DNA Sequence (CDS) identifications of let- genes (Continued)

\begin{tabular}{|c|c|c|c|c|c|c|c|}
\hline let-608/ncbp-1 & h706 & $Q>^{*}$ & Nuclear cap binding protein & RNAi & Confirmed $^{2}$ & NCBP1 & \\
\hline let-611/C48E7.2 & h756 & $\mathrm{Q}>{ }^{*}$ & RNA polymerase III subunit & RNAi & Confirmed $^{2}$ & POLR3C & \\
\hline let-612/apm-1 & h466 & splice variant & Adaptin subunit & RNAi & Confirmed $^{2}$ & AP1M1 & \\
\hline let-365/sep-1 & h108 & $W>*$ & Separase & Both & Confirmed $^{2}$ & ESPL1 & Breast cancer oncogene \\
\hline let-364/mat-1 & h104 & $S>F$ & $\begin{array}{l}\text { Anaphase promoting complex } \\
\text { subunit }\end{array}$ & RNAi & Confirmed $^{2}$ & CDC27 & \\
\hline let-101/npp-6 & h242 & $W>*$ & Nuclear pore complex protein & Both & Confirmed $^{2}$ & NUP160 & \\
\hline let-106/hcp-6 & h787 & $C>Y$ & Condensin subunit & Both & Confirmed $^{2}$ & NCAPD3 & \\
\hline let-379/tag-345 & h127 & $W>*$ & $\begin{array}{l}\text { Nucleolar protein complex } \\
\text { member }\end{array}$ & RNAi & Confirmed $^{2}$ & WDR12 & \\
\hline let-503/R12E2.2 & h313 & $Q>^{*}$ & Protein of unknown function & K.O. & Confirmed $^{2}$ & SUCO & \\
\hline let-517/spg-7 & h264 & $G>E$ & Metalloprotease & Both & Confirmed $^{2}$ & AFG3L2 & Spastic ataxia, Spinocerebellar ataxia \\
\hline let-597/hcp-4 & h349 & $E>*$ & Holocentromeric protein & RNAi & Confirmed $^{2}$ & CENPC & \\
\hline \multirow[t]{2}{*}{$\begin{array}{l}\text { let-630/ } \\
\text { Y110A7A.19 }\end{array}$} & $\mathrm{h} 355^{\mathrm{b}}$ & $\mathrm{R}>*$ & $\begin{array}{l}\text { Pentatricopeptide repeat } \\
\text { containing protein }\end{array}$ & RNAi & Confirmed $^{2}$ & PTCD3 & \\
\hline & $\mathrm{h} 782^{\mathrm{b}}$ & $W>^{*}$ & & & Confirmed $^{2}$ & & \\
\hline let-646/pat-10 & h233 & $G>E$ & Troponin C & RNAi & Confirmed $^{2}$ & TNNC1 & Cardiomyopathy \\
\hline \multirow[t]{2}{*}{ let-526 } & h799 & $\mathrm{Q}>{ }^{*}$ & SWI/SNF complex subunit & Both & Confirmed $^{3}$ & ARID1A & Mental retardation \\
\hline & $\mathrm{h} 405^{\mathrm{c}}$ & $W>^{*}$ & & & Confirmed $^{3}$ & & \\
\hline let-129/zfh-2 & h379 & $Q>*$ & zinc finger homeobox protein & Both & Prediction & ZFHX3, ZFHX4 & $\begin{array}{l}\text { Susceptibility to prostate cancer, } \\
\text { Ptosis }\end{array}$ \\
\hline let-147/rnp-6 & h463 & $G>E$ & RNA splicing factor & $\begin{array}{l}\text { RNAi } \\
\text { range }\end{array}$ & Prediction & PUF60 & Verheij syndrome \\
\hline let-373/unc-73 & h234 & Del & Guanine nucleotide exchange factor & Both & Prediction & TRIO & \\
\hline let-377/lim-7 & h110 & $W>^{*}$ & LIM homeodomain protein & K.O. & Prediction & ISL2 & \\
\hline let-378/dnj-21 & h124 & $G>E$ & DnaJ domain containing protein & RNAi & Prediction & DNAJC15 & \\
\hline let-380/knl-2 & h80 & $W>^{*}$ & Centromeric protein & Both & Prediction & & \\
\hline let-382/nuo-2 & h82 & $Q>*$ & Mitochondria complex I subunit & Both & Prediction & NDUFS3 & $\begin{array}{l}\text { Leigh syndrome, Mitochondrial } \\
\text { complex I deficiency }\end{array}$ \\
\hline let-383/T21G5.6 & h115 & $W>^{*}$ & Protein of unknown function & & Prediction & & \\
\hline let-384/C06A5.1 & h84 & $Q>*$ & Integrator subunit & RNAi & Prediction & INTS1 & \\
\hline let-385/teg-4 & h85 & splice variant & splicing factor & RNAi & Prediction & SF3B3 & \\
\hline let-386/dbr-1 & h117 & $G>E$ & RNA lariat-debranching enzyme & $\begin{array}{l}\text { RNAi } \\
\text { range }\end{array}$ & Prediction & DBR1 & \\
\hline let-391/tag-146 & h91 & $Q>>^{*}$ & Uncharacterized zinc finger protein & K.O. & Prediction & & \\
\hline
\end{tabular}


Table 1 Coding DNA Sequence (CDS) identifications of let- genes (Continued)

\begin{tabular}{|c|c|c|c|c|c|c|c|c|}
\hline let-397/rpb-5 & h228 & $Q>^{*}$ & RNA polymerase II subunit & RNAi & Prediction & POLR2E & & \\
\hline let-400/prpf-4 & h269 & $D>G$ & Pre-mRNA processing factor & RNAi & Prediction & PRPF4B & & {$[55]$} \\
\hline let-509/unc-73 & h142 & $W>*$ & $\begin{array}{l}\text { Guanine nucleotide exchange } \\
\text { factor }\end{array}$ & Both & Prediction & TRIO & & \\
\hline let-527/nhr-23 & h207 & $R>Q$ & Nuclear hormone receptor & Both & Prediction & RORC & & \\
\hline let-534/ahcy-1 & h260 & $Q>^{*}$ & S-adenosylhomocysteine hydrolase & Both & Prediction & AHCY & Hypermethioninemia & \\
\hline let-581/unc-11 & h725 & $A>V$ & clathrin adaptor protein & $\begin{array}{l}\text { RNAi; } \\
\text { Range }\end{array}$ & Prediction & PICALM & $\begin{array}{l}\text { Acute lymphoblastic leukemia, Acute } \\
\text { T-cell lymphoblastic leukemia }\end{array}$ & \\
\hline let-601/cuti-1 & h281 & $Q>^{*}$ & Cuticle regulatory protein & Both & Prediction & & & \\
\hline let-602/T09B4.9 & h283 & $W>^{*}$ & translocase & RNAi & Prediction & TIMM44 & & \\
\hline let-604/mdt-18 & h293 & splice variant & Mediator subunit & RNAi & Prediction & MED18 & & \\
\hline let-605/cye-1 & h312 & $W>*$ & E-type cyclin & Both & Prediction & CCNE1 & & \\
\hline let-614 & h138 & & & & $\begin{array}{l}\text { Tested against F27C } 1.3 \text { but did } \\
\text { not confirm }\end{array}$ & & & \\
\hline let-376 & h130 & & & & $\begin{array}{l}\text { Tested against F55F8.3 but did } \\
\text { not confirm }\end{array}$ & & & \\
\hline let-375 & h241 & & & & $\begin{array}{l}\text { Tested against imb-1 but did not } \\
\text { confirm }\end{array}$ & & & \\
\hline let-387 & h87 & & & & $\begin{array}{l}\text { Tested against pnk-1 but did not } \\
\text { confirm }\end{array}$ & & & \\
\hline let-515 & h730 & & & & $\begin{array}{l}\text { Tested against } r p l-13 \text { but did not } \\
\text { confirm }\end{array}$ & & & \\
\hline let-501 & h714 & & & & $\begin{array}{l}\text { Tested against rpl-4 but did not } \\
\text { confirm }\end{array}$ & & & \\
\hline let-361 & h97 & & & & no candidate & & & \\
\hline let-531 & h733 & & & & no candidate & & & \\
\hline let-576 & h816 & & & & no candidate & & & \\
\hline let-518 & h316 & & & & no candidate & & & \\
\hline let-523 & h751 & & & & no candidate & & & \\
\hline let-525 & h874 & & & & no candidate & & & \\
\hline let-584 & h743 & & & & no candidate & & & \\
\hline
\end{tabular}


provided by genetic mutation highlights the importance of our collection.

\section{Essential genes in $s D p 2$ function in cell cycle and cytokinesis, transcriptional regulation, and RNA processing} To identify the processes that are essential, we investigated the function of our high confidence gene set along with their orthologs in D. melanogaster (fly), S. cerevisiae (yeast), and $H$. sapiens (humans). Essential genes are often conserved due to their important biological roles. Fifty-four of our identified essential genes have readily identifiable orthologs in humans [57] (Table 1). We further categorized each gene into at least one of eight functional groups based on their GO annotations (Figure 1). To have a better picture of the roles of different essential genes, multi-functional genes were categorized into more than one functional group. The cell cycle \& cytokinesis, transcriptional regulation, transport, RNA processing, and transcription categories contained more genes than did the groups representing translation, signal transduction, and the other groups that includes metabolic and structural processes.

Of these eight functional groups, we found three groups that were significantly enriched in the $s D p 2$ region when compared to the non-essential genes in $s D p 2$ : cell cycle \& cytokinesis $\left(\mathrm{p}=3.61 \mathrm{e}^{-9}, \mathrm{x}^{2}\right.$ test), regulation of transcription $\left(\mathrm{p}=6.21 \mathrm{e}^{-8}, \mathrm{X}^{2}\right.$ test $)$, and RNA processing $\left(\mathrm{p}=6.35 \mathrm{e}^{-12}, \mathrm{X}^{2}\right.$ test). Our analysis indicates that members of these processes are enriched in essential genes. We have previously shown that components of the spindle assembly checkpoint are essential for survival [58]. Here we showed that genes in the $s D p 2$ region function in various phases of the cell cycle. For instance, let-380 (knl-2) is critical for loading $h c p-3$ (CENP-A) to chromatin and forming the kinetochore [59]. let-603 (air-2), let-597 (hcp-4), and let-106 (hcp-6) remove cohesions for proper resolution of centromeric connections and segregation of homologous chromosomes during meiosis [60-62]. let-365 (sep-1) is essential for chromatid separation and proper anaphase. In addition, let-364 (mat-1), a member of the anaphase promoting complex (APC), is crucial for the transition from metaphase to anaphase [63]. lin-6 $(\mathrm{mcm}-4)$ is required for DNA replication and activates a checkpoint when entering into $M$ phase [39]. let-599 (nath-10) and let-354 (dhc-1) are crucial for cytokinesis during cell division [64,65]. let385 (teg-4) is a component of splicing complex A that functions in the meiosis entry decision $[66,67]$. Our data indicate that disrupting any phase of the cell cycle process can lead to lethality.

Are functions of the essential genes identified in this study representative of all essential genes? Random sampling simulation from 3500 essential genes indicated by RNAi shows a very different GO term distribution (Figure 1). In the larger set samples, we observed that cell cycle and cytokinesis $\left(p=1.02 \mathrm{e}^{-22}, \mathrm{x}^{2}\right.$ test), regulation of transcription $\left(\mathrm{p}=2.48 \mathrm{e}^{-20}, \chi^{2}\right.$ test), and RNA processing $\left(\mathrm{p}=5.43 \mathrm{e}^{-10}, \chi^{2}\right.$ test $)$ are under-represented compared to our sequenced set. Although we acknowledge that comparing lethal mutants to RNAi phenocopies is not fully equivalent, at the present time there is not a large enough mutant essential gene collection to do this comparison. It is intriquing nevertheless to raise the question of regional differences in essential gene functions and we look forward to having a more complete dataset that can be used to address this issue.

\section{Essential gene transcripts are supplied maternally}

From the set of 59 essential genes, 34 of them arrest development as embryos or early larvae, indicating that they are important early in development. To test this hypothesis, we analyzed the temporal expression of these genes using RNA-seq divided into 23 separate 30-minute embryonic stages, 4 larval stages, pre-gravid young adult stage, and the young adult stage. The normalized RNA-seq data was obtained from the modENCODE project $[68,69]$.

Seven distinct patterns were seen from the heatmap (Figure 2). Five genes (colored red) express highly during mid-embryonic stage (300 min - $600 \mathrm{~min}$ ), six genes (colored blue) express highly during late-embryonic stage (600 min - hatch), and seven genes (colored green) express highly in both mid-embryonic and late-embryonic stages. Eighteen genes (colored purple) show elevated

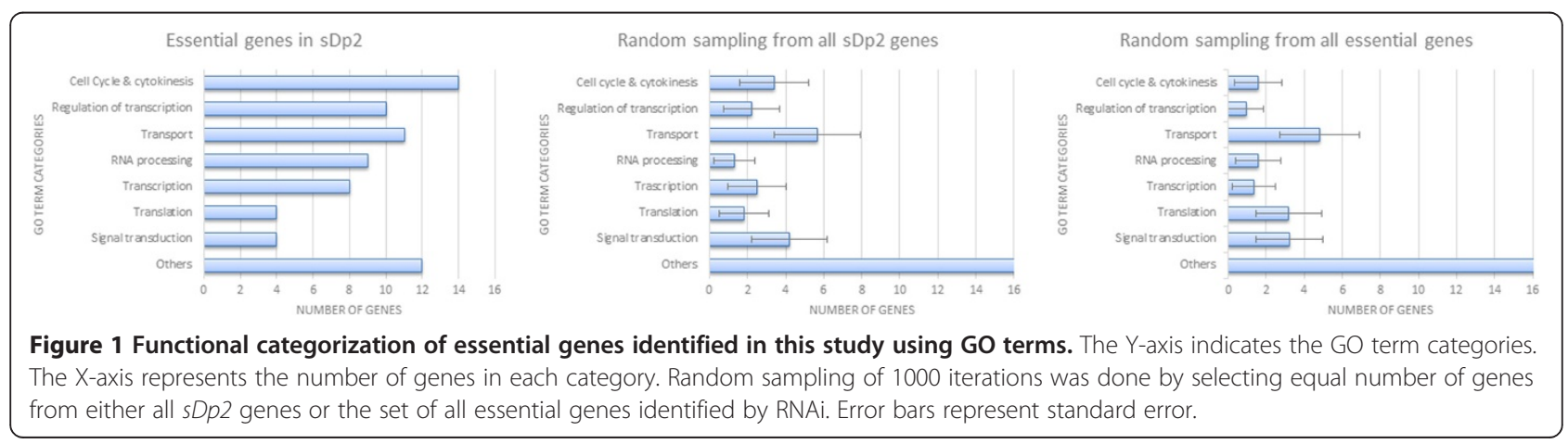




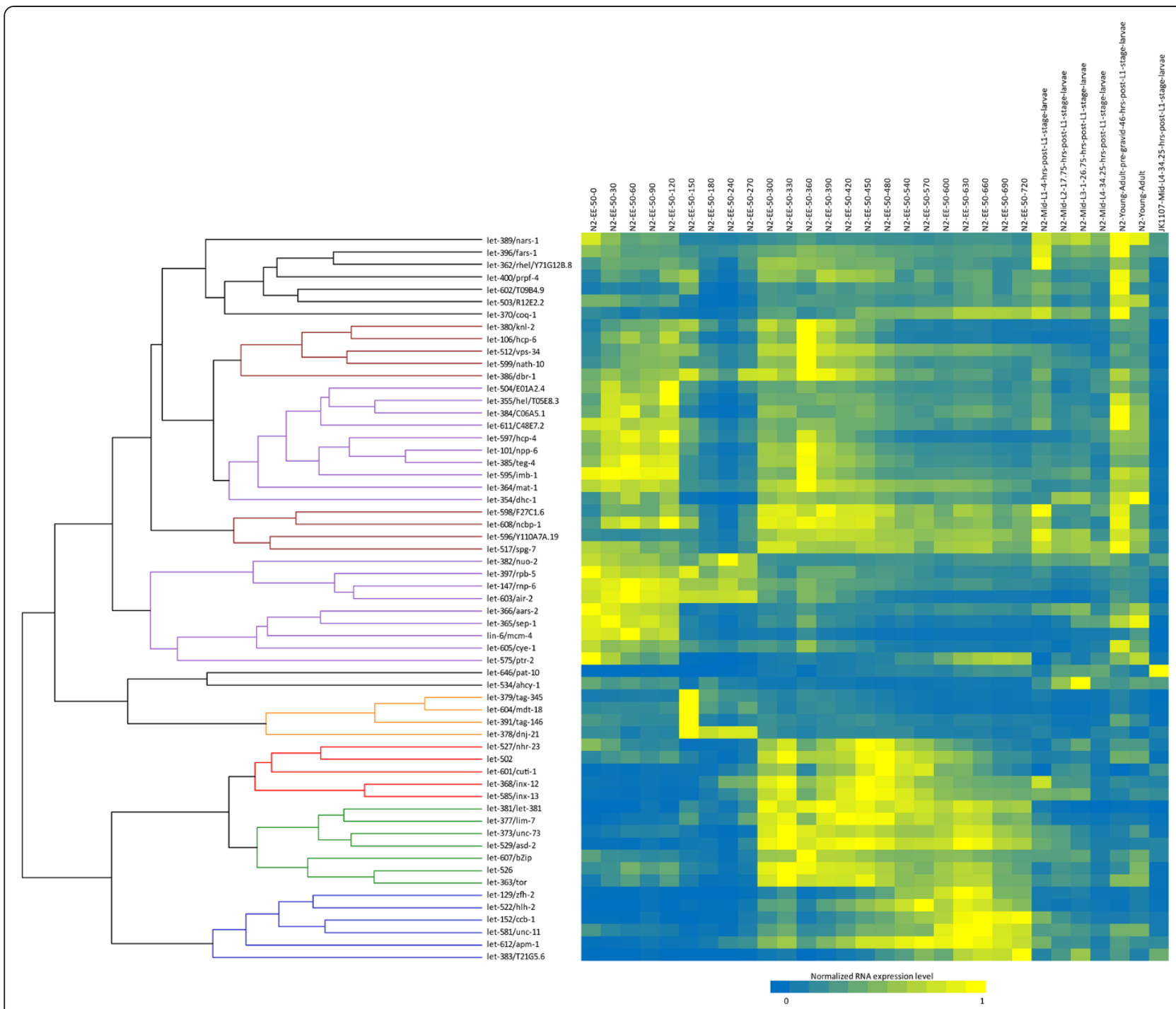

Figure 2 This figure represents the normalized transcript level (read number per coding length per million reads) for each gene across the developmental stages including 23 embryo stages separated by 30 minute interval, four larval stages (L1-L4), pre-gravid young adult, and gravid young adult. For comparing germline expression, we've included the transcript level from JK1107 carrying a mutation in glp-1, which is essential for mitotic germ cell proliferation [71]. The heatmap represents normalized transcript level from high (yellow) to low (blue). Seven distinct clusters that are based on their expression pattern are shown by colored branches. Purple: early-embryonic; Brown: early- and mid-embryonic; Red: mid-embryonic; Blue: late-embryonic; Green: mid- and late-embryonic; Orange: gastrulation; Black: larval.

expression very early in embryonic development $(0 \mathrm{~min}-$ $300 \mathrm{~min})$. Most of these genes, however, had a dramatic drop in expression level at $150 \mathrm{~min}$, which is when gastrulation occurs [70]. Observing that many of these genes also show strong expression in young adults but not in larval stages suggests that these messages are highly transcribed in the germline and are likely maternally derived in the embryo. On the other hand, nine genes (colored brown) show some early embryonic expression but have their strongest expression during mid-embryonic stages. A group of four genes (colored orange) show specific expression during gastrulation. Lastly, eight genes (colored black) have elevated expression during specific larval stages.
From the RNAseq data, we observed 18 genes with expression patterns that indicated maternal contribution during early embryogenesis. This ratio is not significantly different from the set of all essential genes. However, when compared with the set of non-essential genes, our essential gene list is significantly enriched for genes with strong maternal contribution $\left(1.24 \mathrm{e}^{-5}, \mathrm{X}^{2}\right.$ test). These data indicate that many essential genes important for early embryonic development have maternal contribution.

\section{Conclusions}

The function of essential genes is poorly understood. Having a combination of genetic strains for which the 
molecular identity is known would provide a powerful resource for their study. However, even in the model system C. elegans, only about $25 \%$ of the essential genes have a knockout alleles. RNAi has also been used to identify essential genes [72,73]. Despite the success of these studies, only a small subset ( $~ 800$ genes) have been profiled phenotypically [72]. We have a large collection of mutant strains, but only now has it been technically feasible to easily identify their corresponding coding regions. Our library currently consists of 1350 lethal mutations maintained by balancers in chromosomes I, III, IV, and V, of which chromosome I is the closest to saturation [19]. Recent whole genome screening experiments using the CRISPR/Cas9 system have opened up the possibility of identifying essential genes using this targeted approach. However, targeted approaches directed towards identifying essential genes in an intact multicellular organism are still limited in terms of recovery and maintenance of lethal mutations and impractical for large scale screens. The relative ease of capturing and maintaining lethal mutations makes balancer systems the method of choice for essential gene studies. However, using random mutagenesis is not possible to achieve $100 \%$ saturation (finding all essential genes). Small targets have a smaller chance of being mutated and are likely missed in mutagenesis experiments. Also, finding new essential genes in subsequent screenings becomes more and more difficult because the screens follow (approximately) a Poisson distribution giving diminishing returns. Thus, a combination of targeted and forward mutational approaches is best.

We previously developed a pipeline and applied it to the identification of let-504 [30]. In the analysis presented here, we applied the pipeline to further analyze 76 essential genes on Chromosome I and produced high confidence identification for 64 genes. Some of the confirmed candidates were found outside the mapped region suggesting that the boundaries of the genetically identified zones can be further refined. We have shown that our approach is much more efficient and costeffective than the traditional method. Assessments from this study will help us improve our identification pipeline and give us the confidence to apply this technique to the rest of our collection of essential genes.

Our results here provide additional alleles to known genes as well as provide new alleles. The added alleles will be valuable for establishing allelic series that may exhibit different phenotypes. For instance let-147/rnp-6 has 4 alleles each showing a different arrest stage [19], suggesting different protein domains are being disrupted. More importantly, our results provided 13 new alleles in essential genes where no alleles existed. The genetic resources provided with our method will be beneficial to the field of essential gene research.

We have demonstrated here that Let mutants can be used, not only individually to study the gene's function, but analyzed as a group to better understand the functions a living multi-cellular animal needs for survival. Understanding the function of individual essential genes has applications for medicine. Essential genes in bacteria have been exploited to develop new antimicrobials [5]. An understanding of essential genes can be exploited for new medical uses. For example, the human ortholog of let-400/ prpf-4, has been found to induce G1/S arrest and may function as a cancer suppressor [55]. Therefore, a resource such as described here for identifying and studying essential genes in model organisms has direct benefit.

We have shown that essential genes in the left half of chromosome I in C. elegans function in cell cycle control, transcriptional regulation, and RNA processing. Previous reports studying other genomic regions have shown different gene classes such as those regulated by the GATA transcription factor [74] and the sex-regulated genes [75] are non-randomly distributed in the genome. Thus, we believe the organization of these genes within the genome is also non-random. With our method, it is now possible to generate genetic resources to capture the majority of the essential genes. The study of which will provide us with a global picture of the minimum set of genes and pathways that is needed for the survival of a multi-cellular organism, and their organization in the genome. An increased understanding of the nature of essential genes is relevant not only to our knowledge of the biological survival of the organism but also has the potential for better medical procedures.

\section{Methods}

\section{Strains}

The strains used in this study are listed in Table 1. We have listed all the other available alleles for each letgene in Additional file 2. The strains were grown and maintained on nematode growth medium streaked with E. coli OP50 [76]. The strains used in this study were generated by mutagenizing KR235 [dpy-5 (e61), +, unc13 (e450)/dpy-5(e61), unc-15(e73), +; sDp2] with $12 \mathrm{mM}$ EMS [35]. Briefly, the treated gravid wildtypes were individually plated on $5 \mathrm{~cm}$ plates and wildtype gravid F1s were also individually plated 5 days later. Their progeny (F2s) were screened for the absence of Dpy-5 Unc-13 individuals (Additional file 1). A single Unc-13 animal was transferred to confirm the existence of a lethal mutation. A balanced lethal would exhibit Unc-13 and developmentally arrested Dpy-5 Unc-13 [35]. All the strains were maintained at $20^{\circ} \mathrm{C}$ and by selecting Unc animals. Each strain was grown from one hermaphrodite and expanded to 202 -inch plates. The worms were collected by rinsing the plates with $\mathrm{M} 9\left(6 \mathrm{~g} \mathrm{Na} \mathrm{HPO}_{4}, 3 \mathrm{~g}\right.$ $\mathrm{KH}_{2} \mathrm{PO}_{4}, 5 \mathrm{~g} \mathrm{NaCl}, 0.2 \mathrm{~g} \mathrm{MgSO}_{4}$ in $1 \mathrm{~L}$ of $\left.\mathrm{H}_{2} 0\right)$. The worms were washed with $12 \mathrm{ml}$ of $\mathrm{M} 9$ three times and incubated at room temperature for 2 hours. The final pellet was frozen in $-80^{\circ} \mathrm{C}$. 


\section{Genomic DNA extraction and sequencing}

Genomic DNA was extracted by phenol/chloroform as described previously [30]. Briefly, the worm pellet was lysed in $0.5 \%$ SDS and 100ug of Proteinase $\mathrm{K}$ in $50^{\circ} \mathrm{C}$ for two hours. DNA was extracted with phenol/chloroform three times and precipitated with $100 \%$ ethanol. 20 ug of RNase A was added to the eluted sample to remove RNA contaminants and this was followed by three more rounds of phenol/chloroform extraction and ethanol precipitation. 10 ug of purified genomic DNA was sequenced at the BC Cancer Agency Genome Sciences Centre using Illumina PET HiSeq technology.

\section{Mutation identification procedure}

Sequencing reads were aligned to the WS200 C. elegans genome using BWA [36] under default settings. Duplicated reads were filtered with GATK [77]. Further realignment around indels was also done with GATK. The BAM files were analyzed for SNV and small indels using Varscan [78]. The SNVs or indels returned by Varscan were filtered by 1) mutations in the parental strain KR235 mutation, 2) variant ratio $(90 \%>x>40 \%)$, and 3) genomic location (in coding sequences only). Allelic ratio was calculated as the ratio of mutant allele:reference allele. The effect for each CDS from the accumulate effect of the mutations in the genome was analyzed using Coovar [79]. Mutational landscape analysis was done using SNVs exhibiting G > A or $\mathrm{C}>\mathrm{T}$ transitions as described previously [30]. Each genes in the $s D p 2$ carrying a non-synonymous mutation was considered and ranked according to the severity of the mutation. Mapping information from [19] was used as a guide to find the most likely mutation. The mutations for each strain can be downloaded from http://lethal.mbb. sfu.ca/jschu/essential_genes.

Sequencing of a second allele was done with Sanger sequencing or WGS. PCR primers were designed using Primer3 [80,81] spaced 250 bp apart with staggered orientation. This allowed sufficient overlap so that each position was covered at least twice. The Sanger reads were aligned to the wildtype transcript sequence using Clustal [82]. The alignments from each Sanger read were merged and analyzed with Bioedit. A mutation was confirmed if it was supported by all the Sanger reads and the sequencing traces show a clear double peak. A prediction was also confirmed when WGS of a second allele has a different mutation in the same gene.

\section{Confirmation by complementation testing}

Allelic combinations were established previously by complementation testing as described in [19] with the following exceptions. In a few cases, candidate SNVs were found for mutations, which were previously described as mapping to separate zones, in a single coding region. In these cases complementation testing was done between mutations predicted to be in the candidate coding region and confirmed that they did form a single complementation group as shown in Additional file 3.

Strains carrying a lethal mutation were selected for complementation testing with other lethal-carrying strains based on the identification of candidate mutations in the same gene. In order to determine allelism, let- $x d p y-5$ unc13/let-x dpy-5 unc-13; $s D p 2$ hermaphrodites were mated to wild-type males. F1 males (let-x dpy-5 unc-13/ + + +) were crossed to hermaphrodites carrying a second lethal (let-y dpy-5 unc-13/let-y dpy-5 unc-13; sDp2). The diagnostic phenotype indicating complementation in the progeny of the cross was Dpy Unc males and fertile hermaphrodites (let-x dpy-5 unc-13/let-y dpy-5 unc-13). A minimum of ten wild-type males on one plate was considered sufficient to conclude that the absence of Dpy Unc animals was not due to poor mating.

\section{Gene ontology analysis}

Orthologs were predicted by a set of programs consisting of Inparanoid [83], OrthoMCL [84], and Ensembl-Compara [85] with methods as previously described [57]. The protein sets used were: C. elegans (WS230), S. cerevisiae (64-1-1), D. melanogaster (r5.46), and H. sapiens (GRCh37.66). GO annotation was done using Blast2GO [86]. GO profile comparison was done using all the genes under $s D p 2$ and all the essential genes as identified by RNAi collected from WormBase WS230.

\section{RNA-seq expression analysis}

Normalized RNA-seq data were downloaded from the modEncode website (www.modencode.org). The average normalized read count for each CDS was calculated as the total normalized read count of all coding base-pairs divided by the length of CDS. The expression profile clustering was done using agnes clustering in $\mathrm{R}$.

\section{Additional files}

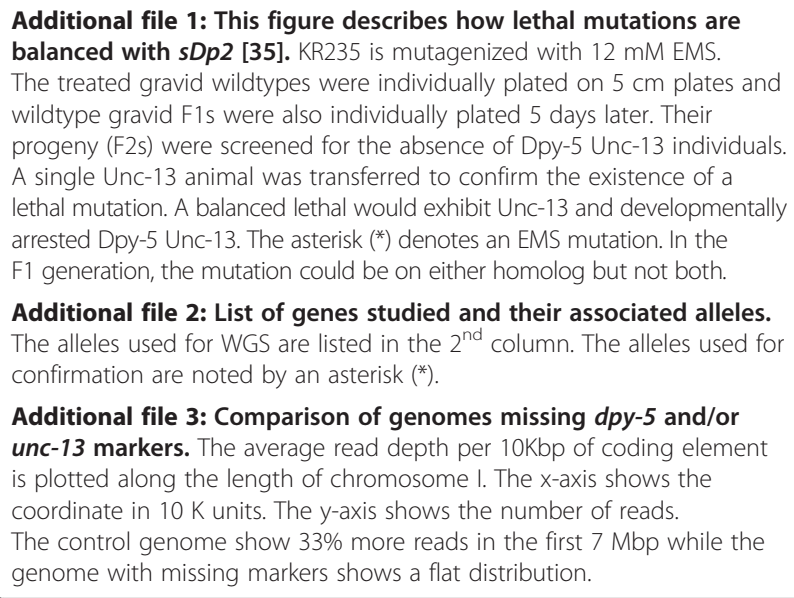

Additional file 3: Comparison of genomes missing $d p y-5$ and/or unc-13 markers. The average read depth per 10Kbp of coding element is plotted along the length of chromosome I. The $x$-axis shows the coordinate in $10 \mathrm{~K}$ units. The $\mathrm{y}$-axis shows the number of reads. The control genome show 33\% more reads in the first $7 \mathrm{Mbp}$ while the genome with missing markers shows a flat distribution. 
Additional file 4: Complementation table for let-363 (h98), let-130 (h216), let-130 (h451), let-631 (h502), let-630 (h355), let-596 (h782), let-526 (h185), let-104 (h799), and let-519 (h405). (-) indicates two mutations fail to complement and $(+)$ indicates two mutations complement each other. N.D. indicates the particular combination was not done.

\section{Abbreviations}

WGS: Whole genome sequencing; SNV: Single nucleotide variation; EMS: Ethyl methanesulfonate; GO: Gene ontology.

\section{Competing interests}

The authors declare that they have no competing interests.

\section{Authors' contributions}

AMR and DLB conceived the project. JSCC, SYC, KW, AMD, and AMR performed the experiments. JSCC, RJ, DLB, and AMR analyzed the data. JSCC, DLB, and AMR wrote the paper. All authors read and approved the final manuscript.

\section{Acknowledgements}

We thank Shir Hazir for his technical support. We also thank Dr. Nansheng Chen and members of the Rose lab for their comments and editing of the manuscript. JSCC is supported by CIHR Fanconi Anemia. AR and DB are supported by CIHR and NSERC.

\section{Author details}

'Department of Medical Genetics, University of British Columbia, Vancouver, Canada. ${ }^{2}$ Department of Molecular Biology and Biochemistry, Simon Fraser University, Burnaby, Canada. ${ }^{3}$ Department of Biology, Kwantlen Polytechnic University, Surrey, Canada.

Received: 5 December 2013 Accepted: 6 May 2014

Published: 12 May 2014

\section{References}

1. Goh Kl, Cusick ME, Valle D, Childs B, Vidal M, Barabasi AL: The human disease network. Proc Natl Acad Sci U S A 2007, 104:8685-8690.

2. Park D, Park J, Park SG, Park T, Choi SS: Analysis of human disease genes in the context of gene essentiality. Genomics 2008, 92:414-418.

3. Dickerson JE, Zhu A, Robertson DL, Hentges KE: Defining the role of essential genes in human disease. PLoS One 2011, 6:e27368.

4. Solimini $\mathrm{NL}, \mathrm{Xu} \mathrm{Q}$, Mermel $\mathrm{CH}$, Liang AC, Schlabach MR, Luo J, Burrows AE, Anselmo AN, Bredemeyer AL, Li MZ, Beroukhim R, Meyerson M, Elledge SJ: Recurrent hemizygous deletions in cancers may optimize proliferative potential. Science 2012, 337:104-109.

5. Juhas M, Eberl L, Church GM: Essential genes as antimicrobial targets and cornerstones of synthetic biology. Trends Biotechnol 2012, 30:601-607.

6. Johnsen RC, Baillie DL: Mutation. In C Elegans II. 2nd edition. Edited by Riddle DL, Blumenthal T, Meyer BJ, Priess JR. NY: Cold Spring Harbor Press; 1997.

7. Ramani AK, Chuluunbaatar T, Verster AJ, Na H, Vu V, Pelte N, Wannissorn N, Jiao A, Fraser AG: The majority of animal genes are required for wild-type fitness. Cell 2012, 148:792-802.

8. Kamath RS, Fraser AG, Dong Y, Poulin G, Durbin R, Gotta M, Kanapin A, Le Bot N, Moreno S, Sohrmann M, Welchman DP, Zipperlen P, Ahringer J: Systematic functional analysis of the Caenorhabditis elegans genome using RNAi. Nature 2003, 421:231-237.

9. Kemphues K: Essential Genes. [http://www.wormbook.org/chapters/ www essentialgenes/essentialgenes.html]

10. Yook K, Harris TW, Bieri T, Cabunoc A, Chan J, Chen WJ, Davis P, de la Cruz N, Duong A, Fang R, Ganesan U, Grove C, Howe K, Kadam S, Kishore R, Lee R, Li Y, Muller HM, Nakamura C, Nash B, Ozersky P, Paulini M, Raciti D, Rangarajan A Schindelman G, Shi X, Schwarz EM, Ann Tuli M, Van Auken K, Wang D, et al: WormBase 2012: more genomes, more data, new website. Nucleic Acids Res 2012, 40:D735-D741.

11. Chen N, Harris TW, Antoshechkin I, Bastiani C, Bieri T, Blasiar D, Bradnam K, Canaran P, Chan J, Chen CK, Chen WJ, Cunningham F, Davis P, Kenny E, Kishore R, Lawson D, Lee R, Muller HM, Nakamura C, Pai S, Ozersky P, Petcherski A, Rogers A, Sabo A, Schwarz EM, Van Auken K, Wang Q, Durbin
R, Spieth J, Sternberg PW, et al: WormBase: a comprehensive data resource for Caenorhabditis biology and genomics. Nucleic Acids Res 2005, 33:D383-D389.

12. Han M, Sternberg PW: let-60, a gene that specifies cell fates during C. elegans vulval induction, encodes a ras protein. Cell 1990, 63:921-931.

13. Grishok A, Pasquinelli AE, Conte D, Li N, Parrish S, Ha I, Baillie DL, Fire A, Ruvkun G, Mello CC: Genes and mechanisms related to RNA interference regulate expression of the small temporal RNAs that control $\mathrm{C}$. elegans developmental timing. Cell 2001, 106:23-34.

14. Hill DA, Ivanovich J, Priest JR, Gurnett CA, Dehner LP, Desruisseau D, Jarzembowski JA, Wikenheiser-Brokamp KA, Suarez BK, Whelan AJ, Williams G, Bracamontes D, Messinger Y, Goodfellow PJ: DICER1 mutations in familial pleuropulmonary blastoma. Science 2009, 325:965.

15. Thompson O, Edgley ML, Strasbourger P, Flibotte S, Ewing B, Adair R, Au V, Chaudhry I, Fernando L, Hutter H, Kieffer A, Lau J, Lee N, Miller A, Raymant G, Shen B, Shendure J, Taylor J, Turner EH, Hillier LW, Moerman DG, Waterston $\mathrm{RH}$ : The million mutation project: a new approach to genetics in Caenorhabditis elegans. Genome Res 2013, 23:1749-1762.

16. C. elegans Deletion Mutant Consortium T: Large-scale screening for targeted knockouts in the Caenorhabditis elegans genome. G3 (Bethesda) 2012, 2:1415-1425.

17. Moerman DG, Barstead RJ: Towards a mutation in every gene in Caenorhabditis elegans. Brief Funct Genomic Proteomic 2008, 7:195-204.

18. Edgley ML, Baillie DL, Riddle DL, Rose AM: Genetic balancers. 2006, http:// www.wormbook.org/chapters/www_geneticbalancers/geneticbalancers.html.

19. Johnsen RC, Jones SJ, Rose AM: Mutational accessibility of essential genes on chromosome I(left) in Caenorhabditis elegans. Mol Gen Genet 2000, 263:239-252.

20. Rose AM, Baillie DL: Genetic organization of the region around UNC-15 (I), a gene affecting paramyosin in Caenorhabditis elegans. Genetics 1980, 96:639-648.

21. Sigurdson DC, Spanier GJ, Herman RK: Caenorhabditis elegans deficiency mapping. Genetics 1984, 108:331-345

22. Stewart HI, O'Neil NJ, Janke DL, Franz NW, Chamberlin HM, Howell AM, Gilchrist EJ, Ha TT, Kuervers LM, Vatcher GP, Danielson JL, Baillie DL: Lethal mutations defining 112 complementation groups in a $4.5 \mathrm{Mb}$ sequenced region of Caenorhabditis elegans chromosome III. Mol Gen Genet 1998, 260:280-288.

23. Clark DV, Rogalski TM, Donati LM, Baillie DL: The unc-22(IV) region of Caenorhabditis elegans: genetic analysis of lethal mutations. Genetics 1988, 119:345-353.

24. Rogalski TM, Baillie DL: Genetic organization of the unc-22 IV gene and the adjacent region in Caenorhabditis elegans. Mol Gen Genet 1985, 201:409-414.

25. Rogalski TM, Moerman DG, Baillie DL: Essential genes and deficiencies in the unc-22 IV region of Caenorhabditis elegans. Genetics 1982, 102:725-736.

26. Clark DV, Baillie DL: Genetic analysis and complementation by germ-line transformation of lethal mutations in the unc-22 IV region of Caenorhabditis elegans. Mol Gen Genet 1992, 232:97-105.

27. Johnsen RC, Baillie DL: Genetic analysis of a major segment [LGV(left)] of the genome of Caenorhabditis elegans. Genetics 1991, 129:735-752.

28. Meneely PM, Herman RK: Suppression and function of X-linked lethal and sterile mutations in Caenorhabditis elegans. Genetics 1981, 97:65-84.

29. Meneely PM, Herman RK: Lethals, steriles and deficiencies in a region of the X chromosome of Caenorhabditis elegans. Genetics 1979, 92:99-115.

30. Chu JS, Johnsen RC, Chua SY, Tu D, Dennison M, Marra M, Jones SJ, Baillie $\mathrm{DL}$, Rose AM: Allelic ratios and the mutational landscape reveal biologically significant heterozygous SNVs. Genetics 2012, 190:1225-1233.

31. Sarin S, Prabhu S, O'Meara MM, Pe'er I, Hobert O: Caenorhabditis elegans mutant allele identification by whole-genome sequencing. Nat Methods 2008, 5:865-867

32. Rose AM, O'Neil NJ, Bilenky M, Butterfield YS, Malhis N, Flibotte S, Jones MR, Marra M, Baillie DL, Jones SJ: Genomic sequence of a mutant strain of Caenorhabditis elegans with an altered recombination pattern. BMC Genomics 2010, 11:131.

33. Shen Y, Sarin S, Liu Y, Hobert O, Pe'er I: Comparing platforms for $C$. elegans mutant identification using high-throughput whole-genome sequencing. PLoS One 2008, 3:e4012.

34. Zuryn S, Le Gras S, Jamet K, Jarriault S: A strategy for direct mapping and identification of mutations by whole-genome sequencing. Genetics 2010, 186:427-430. 
35. Howell AM, Gilmour SG, Mancebo RA, Rose AM: Genetic analysis of a large autosomal region in Caenorhabditis elegans by the use of a free duplication. Genet Res 1987, 49:207-213.

36. Li H, Durbin R: Fast and accurate short read alignment with BurrowsWheeler transform. Bioinformatics 2009, 25:1754-1760.

37. Rose AM, Baillie DL, Curran J: Meiotic pairing behavior of two free duplications of linkage group I in Caenorhabditis elegans. Mol Gen Genet 1984, 195:52-56.

38. Flibotte S, Edgley ML, Chaudhry I, Taylor J, Neil SE, Rogula A, Zapf R, Hirst M, Butterfield Y, Jones SJ, Marra MA, Barstead RJ, Moerman DG: Wholegenome profiling of mutagenesis in Caenorhabditis elegans. Genetics 2010, 185:431-441.

39. Korzelius J, The I, Ruijtenberg S, Portegijs V, Xu H, Horvitz HR, van den Heuvel S: C. elegans MCM-4 is a general DNA replication and checkpoint component with an epidermis-specific requirement for growth and viability. Dev Biol 2011, 350:358-369.

40. Lye RJ, Wilson RK, Waterston RH: Genomic structure of a cytoplasmic dynein heavy chain gene from the nematode Caenorhabditis elegans. Cell Motil Cytoskeleton 1995, 32:26-36.

41. O'Rourke SM, Dorfman MD, Carter JC, Bowerman B: Dynein modifiers in C. elegans: light chains suppress conditional heavy chain mutants. PLoS Genet 2007, 3:e128.

42. Gil-Krzewska AJ, Farber E, Buttner EA, Hunter CP: Regulators of the actin cytoskeleton mediate lethality in a Caenorhabditis elegans dhc-1 mutant. Mol Biol Cell 2010, 21:2707-2720.

43. Wissmann A, Ingles J, McGhee JD, Mains PE: Caenorhabditis elegans LET-502 is related to Rho-binding kinases and human myotonic dystrophy kinase and interacts genetically with a homolog of the regulatory subunit of smooth muscle myosin phosphatase to affect cell shape. Genes Dev 1997, 11:409-422.

44. Long X, Spycher C, Han ZS, Rose AM, Muller F, Avruch J: TOR deficiency in C. elegans causes developmental arrest and intestinal atrophy by inhibition of mRNA translation. Curr Biol 2002, 12:1448-1461.

45. Holzenberger M, Dupont J, Ducos B, Leneuve P, Geloen A, Even PC, Cervera $P$, Le Bouc $Y$ : IGF-1 receptor regulates lifespan and resistance to oxidative stress in mice. Nature 2003, 421:182-187.

46. Woollard A, Hodgkin J: Stu-7/air-2 is a C. elegans aurora homologue essential for chromosome segregation during embryonic and post-embryonic development. Mech Dev 1999, 82:95-108.

47. Roggo L, Bernard V, Kovacs AL, Rose AM, Savoy F, Zetka M, Wymann MP Muller F: Membrane transport in Caenorhabditis elegans: an essential role for VPS34 at the nuclear membrane. EMBO J 2002, 21:1673-1683.

48. Amin NM, Shi H, Liu J: The FoxF/FoxC factor LET-381 directly regulates both cell fate specification and cell differentiation in C. elegans mesoderm development. Development 2010, 137:1451-1460.

49. McDowall JS, Rose A: Alignment of the genetic and physical maps in the dpy-5 bli-4 (I) region of $C$. elegans by the serial cosmid rescue of lethal mutations. Mol Gen Genet 1997, 255:78-95.

50. Zhao Z, Hashiguchi A, Hu J, Sakiyama Y, Okamoto Y, Tokunaga S, Zhu L, Shen $\mathrm{H}$, Takashima $\mathrm{H}$ : Alanyl-tRNA synthetase mutation in a family with dominant distal hereditary motor neuropathy. Neurology 2012, 78:1644-1649.

51. Schapira AH, Mann VM, Cooper JM, Dexter D, Daniel SE, Jenner P, Clark JB, Marsden CD: Anatomic and disease specificity of NADH CoQ1 reductase (complex I) deficiency in Parkinson's disease. J Neurochem 1990, 55:2142-2145.

52. Pinto D, Pagnamenta AT, Klei L, Anney R, Merico D, Regan R, Conroy J, Magalhaes TR, Correia C, Abrahams BS, Almeida J, Bacchelli E, Bader GD, Bailey AJ, Baird G, Battaglia A, Berney T, Bolshakova N, Bolte S, Bolton PF, Bourgeron T, Brennan S, Brian J, Bryson SE, Carson AR, Casallo G, Casey J, Chung $\mathrm{BH}$, Cochrane L, Corsello C, et al: Functional impact of global rare copy number variation in autism spectrum disorders. Nature 2010, 466:368-372.

53. Marshall CR, Noor A, Vincent JB, Lionel AC, Feuk $L$, Skaug J, Shago M Moessner R, Pinto D, Ren Y, Thiruvahindrapduram B, Fiebig A, Schreiber S, Friedman J, Ketelaars CE, Vos YJ, Ficicioglu C, Kirkpatrick S, Nicolson R, Sloman L, Summers A, Gibbons CA, Teebi A, Chitayat D, Weksberg R, Thompson A, Vardy C, Crosbie V, Luscombe S, Baatjes R, et al: Structural variation of chromosomes in autism spectrum disorder. Am J Hum Genet $2008,82: 477-488$.

54. Noor A, Whibley A, Marshall CR, Gianakopoulos PJ, Piton A, Carson AR, Orlic-Milacic M, Lionel AC, Sato D, Pinto D, Drmic I, Noakes C, Senman L, Zhang X, Mo R, Gauthier J, Crosbie J, Pagnamenta AT, Munson J, Estes AM,
Fiebig A, Franke A, Schreiber S, Stewart AF, Roberts R, McPherson R, Guter SJ, Cook EH Jr, Dawson G, Schellenberg GD, et al: Disruption at the PTCHD1 locus on Xp22.11 in autism spectrum disorder and intellectual disability. Sci Transl Med 2010, 2:49ra68.

55. Liu RY, Diao CF, Zhang Y, Wu N, Wan HY, Nong XY, Liu M, Tang H: miR-371$5 p$ down-regulates pre mRNA processing factor 4 homolog $B$ (PRPF4B) and facilitates the G1/S transition in human hepatocellular carcinoma cells. Cancer Lett 2013, 335:351-360.

56. McDowall JS, Rose AM: Genetic analysis of sterile mutants in the dpy-5 unc-13 (I) genomic region of Caenorhabditis elegans. Mol Gen Genet 1997, 255:60-77.

57. Shaye DD, Greenwald I: OrthoList: a compendium of $C$. elegans genes with human orthologs. PLoS One 2011, 6:e20085.

58. Kitagawa R, Rose AM: Components of the spindle-assembly checkpoint are essential in Caenorhabditis elegans. Nat Cell Biol 1999, 1:514-521.

59. Maddox PS, Hyndman F, Monen J, Oegema K, Desai A: Functional genomics identifies a Myb domain-containing protein family required for assembly of CENP-A chromatin. J Cell Biol 2007, 176:757-763.

60. Kaitna S, Pasierbek P, Jantsch M, Loidl J, Glotzer M: The aurora B kinase AIR-2 regulates kinetochores during mitosis and is required for separation of homologous Chromosomes during meiosis. Curr Biol 2002, 12:798-812.

61. Rogers E, Bishop JD, Waddle JA, Schumacher JM, Lin R: The aurora kinase AIR-2 functions in the release of chromosome cohesion in Caenorhabditis elegans meiosis. J Cell Biol 2002, 157:219-229.

62. Moore LL, Stanvitch G, Roth MB, Rosen D: HCP-4/CENP-C promotes the prophase timing of centromere resolution by enabling the centromere association of HCP-6 in Caenorhabditis elegans. Mol Cell Biol 2005, 25:2583-2592.

63. Shakes DC, Sadler PL, Schumacher JM, Abdolrasulnia M, Golden A: Developmental defects observed in hypomorphic anaphase-promoting complex mutants are linked to cell cycle abnormalities. Development 2003, 130:1605-1620.

64. Shen Q, Zheng X, McNutt MA, Guang L, Sun Y, Wang J, Gong Y, Hou L, Zhang B: NAT10, a nucleolar protein, localizes to the midbody and regulates cytokinesis and acetylation of microtubules. Exp Cell Res 2009, 315:1653-1667.

65. Schmidt DJ, Rose DJ, Saxton WM, Strome S: Functional analysis of cytoplasmic dynein heavy chain in Caenorhabditis elegans with fast-acting temperature-sensitive mutations. Mol Biol Cell 2005, 16:1200-1212.

66. Bruder MB, Mogro-Wilson C, Kerins GJ: A survey assessing the presence of "medical home" for adults with disabilities in Connecticut. Conn Med 2010, 74:341-348.

67. Mantina P, MacDonald L, Kulaga A, Zhao L, Hansen D: A mutation in teg-4, which encodes a protein homologous to the SAP130 pre-mRNA splicing factor, disrupts the balance between proliferation and differentiation in the C. elegans germ line. Mech Dev 2009, 126:417-429.

68. Contrino S, Smith RN, Butano D, Carr A, Hu F, Lyne R, Rutherford K, Kalderimis A, Sullivan J, Carbon S, Kephart ET, Lloyd P, Stinson EO, Washington NL, Perry MD, Ruzanov P, Zha Z, Lewis SE, Stein LD, Micklem G: modMine: flexible access to modENCODE data. Nucleic Acids Res 2012, 40:D1082-D1088.

69. Gerstein MB, Lu ZJ, Van Nostrand EL, Cheng C, Arshinoff BI, Liu T, Yip KY, Robilotto R, Rechtsteiner A, Ikegami K, Alves P, Chateigner A, Perry M, Morris M, Auerbach RK, Feng X, Leng J, Vielle A, Niu W, Rhrissorrakrai K, Agarwal A, Alexander RP, Barber G, Brdlik CM, Brennan J, Brouillet JJ, Carr A, Cheung MS, Clawson H, Contrino S, et al: Integrative analysis of the Caenorhabditis elegans genome by the modENCODE project. Science 2010, 330:1775-1787.

70. Sulston JE, Schierenberg E, White JG, Thomson JN: The embryonic cell lineage of the nematode Caenorhabditis elegans. Dev Biol 1983 100:64-119.

71. Austin J, Kimble J: glp-1 is required in the germ line for regulation of the decision between mitosis and meiosis in C. elegans. Cell 1987 51:589-599.

72. Green RA, Kao HL, Audhya A, Arur S, Mayers JR, Fridolfsson HN, Schulman M, Schloissnig S, Niessen S, Laband K, Wang S, Starr DA, Hyman AA, Sched T, Desai A, Piano F, Gunsalus KC, Oegema K: A high-resolution C. elegans essential gene network based on phenotypic profiling of a complex tissue. Cell 2011, 145:470-482.

73. Sonnichsen B, Koski LB, Walsh A, Marschall P, Neumann B, Brehm M, Alleaume AM, Artelt J, Bettencourt P, Cassin E, Hewitson M, Holz C, Khan M, 
Lazik S, Martin C, Nitzsche B, Ruer M, Stamford J, Winzi M, Heinkel R, Roder M, Finell J, Hantsch H, Jones SJ, Jones M, Piano F, Gunsalus KC, Oegema K, Gonczy P, Coulson A, et al: Full-genome RNAi profiling of early embryogenesis in Caenorhabditis elegans. Nature 2005, 434:462-469.

74. Pauli F, Liu Y, Kim YA, Chen PJ, Kim SK: Chromosomal clustering and GATA transcriptional regulation of intestine-expressed genes in C. elegans. Development 2006, 133:287-295.

75. Reinke V, Gil IS, Ward S, Kazmer K: Genome-wide germline-enriched and sex-biased expression profiles in Caenorhabditis elegans. Development 2004, 131:311-323

76. Brenner S: The genetics of Caenorhabditis elegans. Genetics 1974, 77:71-94.

77. McKenna A, Hanna M, Banks E, Sivachenko A, Cibulskis K, Kernytsky A, Garimella K, Altshuler D, Gabriel S, Daly M, DePristo MA: The Genome Analysis Toolkit: a MapReduce framework for analyzing next-generation DNA sequencing data. Genome Res 2010, 20:1297-1303.

78. Koboldt DC, Zhang Q, Larson DE, Shen D, McLellan MD, Lin L, Miller CA, Mardis ER, Ding L, Wilson RK: VarScan 2: somatic mutation and copy number alteration discovery in cancer by exome sequencing. Genome Res 2012, 22:568-576.

79. Vergara IA, Frech C, Chen N: CooVar: Co-occurring variant analyzer. BMC Res Notes 2012, 5:615.

80. Untergasser A, Cutcutache I, Koressaar T, Ye J, Faircloth BC, Remm M, Rozen SG: Primer3-new capabilities and interfaces. Nucleic Acids Res 2012, 40:e115.

81. Koressaar T, Remm M: Enhancements and modifications of primer design program Primer3. Bioinformatics 2007, 23:1289-1291.

82. Larkin MA, Blackshields G, Brown NP, Chenna R, McGettigan PA, McWilliam $H$, Valentin F, Wallace IM, Wilm A, Lopez R, Thompson JD, Gibson TJ, Higgins DG: Clustal W and Clustal X version 2.0. Bioinformatics 2007, 23:2947-2948

83. Ostlund G, Schmitt T, Forslund K, Kostler T, Messina DN, Roopra S, Frings O, Sonnhammer EL: InParanoid 7: new algorithms and tools for eukaryotic orthology analysis. Nucleic Acids Res 2010, 38:D196-D203.

84. Chen F, Mackey AJ, Stoeckert CJ Jr, Roos DS: OrthoMCL-DB: querying a comprehensive multi-species collection of ortholog groups. Nucleic Acids Res 2006, 34:D363-D368.

85. Vilella AJ, Severin J, Ureta-Vidal A, Heng L, Durbin R, Birney E: EnsemblCompara GeneTrees: Complete, duplication-aware phylogenetic trees in vertebrates. Genome Res 2009, 19:327-335.

86. Conesa A, Gotz S, Garcia-Gomez JM, Terol J, Talon M, Robles M: Blast2GO: a universal tool for annotation, visualization and analysis in functional genomics research. Bioinformatics 2005, 21:3674-3676.

doi:10.1186/1471-2164-15-361

Cite this article as: Chu et al:: High-throughput capturing and characterization of mutations in essential genes of Caenorhabditis elegans. BMC Genomics 2014 15:361.

\section{Submit your next manuscript to BioMed Central and take full advantage of:}

- Convenient online submission

- Thorough peer review

- No space constraints or color figure charges

- Immediate publication on acceptance

- Inclusion in PubMed, CAS, Scopus and Google Scholar

- Research which is freely available for redistribution 